\title{
Biochar Production from Agricultural Wastes via Low-Temperature Microwave Carbonization
}

\author{
Department of Chemistry, Faculty of Resource Science and \\ Technology ${ }^{1}$ \\ Centre of Pre-University Studies ${ }^{2}$ \\ Department of Mechanical and Manufacturing Engineering, \\ Faculty of Engineering ${ }^{3}$ \\ Universiti Malaysia Sarawak, 94300 \\ Kota Samarahan, Sarawak, Malaysia \\ wrafeah@unimas.my;nzainab@unimas.my
}

Rafeah Wahi ${ }^{1}$, Sharifah Mona Abdul Aziz ${ }^{2}$, Sinin Hamdan ${ }^{3}$, Zainab Ngaini ${ }^{1}$ evaluate its potential applications.

\section{A. Materials}

\begin{abstract}
Biochar production from agricultural wastes via low temperature microwave pyrolysis is discussed in the present work as an alternative to the time and energy consuming conventional carbonization. The characteristics of biochar produced from palm kernel shell (PKC), wood chips (WCC) and sago waste (SWC) produced from microwave pyrolysis were investigated. The maximum calorific value of PKC, WCC and SWC in this study was $29.04,24.89$ and $25.99 \mathrm{MJ} / \mathrm{kg}$ respectively. FTIR analysis reveals that the biochars contain $\mathrm{O}-\mathrm{H}, \mathrm{C}-\mathrm{H}$ and $\mathrm{C}=\mathrm{C}$ functional groups, while the SEM analysis showed the formation of porous structure of biochars carbonized at lower temperature for all samples. Results indicated the potential use of these biochar as fuel material and precursor for activated carbon.
\end{abstract}

Keywords- Biochar, microwave, pyrolysis, sago waste, palm kernel shell, wood chips

\section{INTRODUCTION}

Biochar is a light and highly porous carbonaceous material derived from thermochemical decomposition of biomass. In the past decade, there has been an increasing attention in biochar related research due to its versatile applications. The most significant benefit of biochar perhaps is its use in carbon sequestration and as soil amendment agent [1], [2]. Biochar can also be utilized as feedstock for many processes, depending on its physicochemical characteristics. For example, biochar with low ash content can be used as fuel material [3], [4], either alone or together with other types of fuel. Biochar is also potential feedstock for the production of activated carbon [5], [6], catalysts [7], carbon nano-filaments [8] and hydrogasification [9].

Biochar is conventionally produced through high temperature carbonization via electrical, external heating. This process is usually time and energy consuming. Microwave pyrolysis is preferred for it is a time, cost and energy saving means for biochar production [10]-[12]. In this study, the main objective was to produce biochar from agricultural wastes namely palm kernel shell (PK), wood chips (WC) and sago This project is funded by Ministry of Science and Innovation of Malaysia and Universiti Malaysia Sarawak (PRGS/TK04(01)/1268/2015(02)). waste (SW) via microwave pyrolysis. The physicochemical characteristics of the resulting biochar was examined to

\section{MATERIALS AND METHOD}

The agricultural wastes samples used in this study were palm kernel shell (PK), wood chips (WC) and sago wastes (SW) obtained from Sarawak, Malaysia. All samples were sun dried to remove moisture, ground by laboratory grinder (Retsch SM100) and sieved. Particles that passed through $1 \mathrm{~mm}$ sieve were further used for the characterization and microwave pyrolysis experiment. Biochar produced was characterized by proximate analyses (ASTM D-3173, ASTM D-3174 and ASTM D-3175), ultimate analysis (CHN Elemental Analyzer Flash EA1112), calorific value (Shimadzu auto-calculating bomb calorimeter CA-4AJ), Fourier Transform Infrared (FTIR) analysis (Perkin Elmer Spectrum GX) and Scanning Electron Microscopy (SEM) analysis (JSM-6390LA).

\section{B. Microwave Pyrolysis}

The agricultural wastes samples were dried and pyrolyzed in a single process using a modified household microwave oven with input power $1000 \mathrm{~W}$ and frequency of $2450 \mathrm{MHz}$ (SHARP Convection Microwave oven R958A). The experiments were carried out by charring $10 \mathrm{~g}$ of samples in a quartz flask, which was placed inside the microwave oven. Nitrogen gas with the flow rate of 500 $\mathrm{ml} / \mathrm{min}$ was purged into the quartz flask for $30 \mathrm{~min}$ prior to the experiment, and reduced to $100 \mathrm{ml} / \mathrm{min}$ during pyrolysis.

The effect of pyrolysis heating time on biochar characteristics was investigated. Both PK and WC sample was pyrolyzed at 3, 5, 7 and 10 min heating time while SW at 2,3 and $4 \mathrm{~min}$ heating time due to its fast thermal degradability [13]. The temperature of the sample (Table 1) during experiments was monitored using infrared camera (Model: Therma CAM P65). The temperature achieved during the microwave pyrolysis was considerably lower $\left(245-390{ }^{\circ} \mathrm{C}\right)$ compared to conventional carbonization $\left(500-1000{ }^{\circ} \mathrm{C}\right)$. 